\title{
The Impact of the Certainty of Information on COVID-19 Attitudes in Spanish University Teachers and Students
}

\author{
Ricardo de la Vega ${ }^{1}$, Roberto Ruíz Barquín ${ }^{2}$, Szilvia Boros ${ }^{3}$, and Attila Szabo ${ }^{3,4}$ \\ ${ }^{1}$ Department of Physical Education, Sport and Human Movement, Autonomous University of \\ Madrid, Madrid, Spain \\ ${ }^{2}$ Department of Developmental and Educational Psychology, Autonomous University of \\ Madrid, Madrid, Spain \\ ${ }^{3}$ Institute of Health Promotion and Sport Sciences, Eötvös Loránd University, Budapest, \\ Hungary \\ ${ }^{4}$ Institute of Psychology, Eötvös Loránd University, Budapest, Hungary
}

\section{Author Note}

The authors have no conflict of interest to declare.

No financial support was received for this study.

Authors ORCID ID:

Ricardo De La Vega https://orcid.org/0000-0002-7395-3297

Szilvia Boros https://orcid.org/0000-0001-7212-3067

Attila Szabo https://orcid.org/0000-0003-2788-4304

All authors contributed to the study conception and design. Material preparation and data collection were performed by Ricardo de La Vega and Roberto Ruíz-Barquin. Data analyses were performed by Attila Szabo and Szilvia Boros. The first draft of the paper was written by Attila Szabo and all authors commented on previous versions of the manuscript. All authors read and approved the final manuscript.

Correspondence concerning this article should be addressed to Prof. Attila Szabo, Ph.D., D.Sc., Institute of Psychology and Institute of Health Promotion and Sport Sciences, Faculty of Education and Psychology, ELTE Eötvös Loránd University, 1117 Budapest, Bogdánfy u. 10, Hungary. Telephone: +3670243 7123, E-mail: szabo.attila@ppk.elte.hu, ORCID: https://orcid.org/0000-0003-2788-4304 


\begin{abstract}
The COVID-19 pandemic affects the whole world. Spain is one of the most affected nations. Prevention via information that fosters knowledge, reasonable concern, control and personal care is the most effective means to slow down the pandemic. In this intervention study we assessed extant knowledge, concern, control and care about the COVID-19 in 111 Spanish university teachers and students. Subsequently, we randomly assigned them to two groups. One group $(n=53)$ received uncertain information about the current measures of prevention whereas the other group $(n=58)$ received certain information. A group by time interaction revealed that the 'certain information' group reported immediately increased personal care about the pandemic. These findings suggest that measures known to be effective in COVID-19 prevention should be communicated with certainty (i.e. must be convincing) to influence people's attitudes through the schematic organization of new information.
\end{abstract}

Keywords: adults, coronavirus, epidemic, morbidity, virus

\title{
Introduction
}

The outbreak of the new coronavirus disease 2019 (COVID-19) on March 11, 2020 was described as a pandemic by the World Health Organization's Director General (WHO, 2020, March 11). Spain is one of the most affected nations. Since there is no treatment for, or vaccine against, the COVID-19, prevention is the best alternative in combating the pandemic (Heymann \& Shindo, 2020). People's attitudes are reflected in their schemas, but new events like the COVID-19 situations have no antecedent schemas. The threat of COVID-19 outbreak is surrounded by uncertainty. It is known that certain and uncertain information are processed in different brain areas (Ploghaus et al., 2003). Based on the schema theory (Axelrod, 1973), certain information form new and enduring schemas, while uncertain information may either dissipate or form quickly restructured schemas. At time of pandemic the preventive attitudes, translating into actual behaviors, are affected by the level of trust in national measures (Van der Weerd et al., 2011). These attitudes are shaped by new information (Roskos-Ewoldsen et al., 2007). How credible (perceived as certain) this information is, based on schema theory, predicts the public's attitude and compliance with safety measures of the governments, which in turn are crucial in the control of the pandemic (Heymann \& Shindo, 2020).

The objective of the current work was test how held opinions are affected by certain and uncertain information. Based on the schema theory (Axelrod, 1973), we presumed that Spanish people have ambivalent schemas toward COVID-19 that can be quickly and easily influenced by certain, but not uncertain information.

\section{Methods}

The required sample size was calculated with the $G^{*}$ Power (v.3.1) software (Faul et al., 2009). Input: four repeated measures, medium effect size $(f)=.25, \alpha=.05, r=.50$, and power $(1-B)=$ .90. This calculation yielded a minimum required sample size of 108 , so we aimed to recruit slightly more participants via personal solicitations and campus-wide poster boards. The study was conducted with approval from the Research Ethics Board of University (Registration No. CEI106-2060). Consenting students and teachers ( $n=111,63 \%$ women, $M_{\text {age }}=25.04, S D=9.44$, range 18-64 years) rated their perceived: 1) knowledge, 2) concern, 3) control, and 4) personal care about the COVID-19 pandemic in Spain in a large lecture hall with distanced seating. Questions were rated on an 11-point Likert scale ranging from 0 (not at all) to 10 (very much). After the baseline measures, participants were assigned to two groups going into different lecture halls. One group $(n=53)$ received the information about the actual measures in fighting COVID-19 with an uncertain 
conclusion that: 'These measures are quite general, and it is not known how effective they are'. The other group received identical information with certain conclusion that: 'These measures are very specific, clear and effective'. Subsequently, they rated the four measures again. Data collection took place in March 2020, two days prior the University's closure and the lockdown in Spain.

\section{Results}

Data were analyzed with a multivariate repeated measures analyses of covariance. The two (group) by two (gender) by two (time) by four (dependent measures) analysis, controlling for age and university function (teacher/student), only resulted in a statistically significant group by time interaction (Pillai's trace $=.240, F[4,102]=8.04, p<.001$, effect size $\left[\eta^{2}{ }^{2}\right]=.240$ ). Function and age were not significant moderators. The univariate tests revealed that the interaction was statistically significant in two out of the four measures: knowledge $\left(F[1,105]=4.84, p=.03, \eta^{2}{ }_{p}=.044\right)$ and care $\left(F[1,106]=19.45, p<.001, \eta_{p}{ }_{p}=.156\right)$. However, after Bonferroni-corrected post-hoc $t$-tests, statistical significance was only observed in the ratings of care $(t[109]=-6.59, p<.001$, effect size [Cohen's $d$ ] $=1.29$ ) with the certain information group scoring higher than the uncertain information group (Figure 1).

We also calculated difference scores by subtracting baseline from post-intervention values and classified them into three directional categories: decrease, no change, and increase. To examine group differences in the frequencies of the direction of changes in the dependent measures, we performed chi-squares tests. These tests indicated that the two groups differed in all four dependent measures (Table 1).

Insert Table 1 and Figure 1 about here

\section{Discussion}

In accord with our hypothesis, the findings suggest that existing attitudes toward COVID-19 could be influenced more by the certain than uncertain information. Further, more respondents reported increased knowledge and decreased concern in the uncertain than certain group, while more individuals reported increased control and care in the certain than uncertain information group (Table 1). Perceived personal care, which differentiated the groups after the intervention (Figure 1), was largely (85\%) unchanged in the uncertain information group whereas $71 \%$ of the participants in the certain information group reported increased personal care. The practical implication of the current results is simple and straightforward: messages aimed at COVID-19 prevention should be communicated with high level of certainty, which in turn has the potential to affect people's attitudes that are crucial in prevention. This form of message transmission, aimed at influencing the audience, is known as framing (Scheufele \& Tewksbury, 2007) and targets primarily the cognitive, rather than the affective, component in the dual processing of attitudes (Epstein \& Pacini, 1999).

Our results agree with a recent report in which controversial health-related messages, presented with credibility, were immediately adopted and maintained even one week later by the participants (Szabo, 2020). Framing is a sort of manipulation and its content may not be valid but its mode of presentation (certainty) makes it sound factual and, hence, could affect personal attitudes. Certainty promotes credibility which plays role in the schema classification of new information (Greer, 2003). Credibility affects attitudes in function of the involvement level (Stiff, 1986). Therefore, variability in the effect of certainty of information in function of COVID-19 risk groups may be expected and future studies should address this question. Still, COVID-19 information should be communicated with the frame of certainty (Olausson, 2009) to establish legitimay and to impact the majority's compliance with preventive measures. 


\section{References}

Axelrod, R. (1973). Schema theory: An information processing model of perception and cognition. American Political Science Review, 67(4), 1248-1266. https://doi.org/10.2307/1956546

Epstein, S., \& Pacini, R. (1999). Some basic issues regarding dual-process theories from the perspective of cognitive-experiential self-theory. In S. Chaiken \&Y. Trope (Eds.), Dual-process theories in social psychology (pp. 441-461).New York: Guilford Press.

Faul, F., Erdfelder, E., Buchner, A., \& Lang, A.-G. (2009). Statistical power analyses using G*Power 3.1: Tests for correlation and regression analyses. Behavior Research Methods, 41(4), 1149-1160. https://doi.org/10.3758/brm.41.4.1149

Greer, J. D. (2003). Evaluating the credibility of online information: A test of source and advertising influence. Mass Communication and Society, 6(1), 11-28. https://doi.org/10.1207/S15327825MCS0601 3

Heymann, D. L., \& Shindo, N. (2020). COVID-19: what is next for public health? The Lancet, 395(10224), 542-545. https://doi.org/10.1016/s0140-6736(20)30374-3

Olausson, U. (2009). Global warming-global responsibility? Media frames of collective action and scientific certainty. Public Understanding of Science, 18(4), 421-436. https://doi.org/10.1177/0963662507081242

Ploghaus, A., Becerra, L., Borras, C., \& Borsook, D. (2003). Neural circuitry underlying pain modulation: expectation, hypnosis, placebo. Trends in Cognitive Sciences, 7(5), 197-200. https://doi.org/10.1016/s1364-6613(03)00061-5

Roskos-Ewoldsen, D. R., Klinger, M. R., \& Roskos-Ewoldsen, B. B. (2007). Media priming: A metaanalysis. In R. W. Preiss, B. M. Gayle, N. Burrell, M. Allen, \& J. Bryant (Eds.), Mass media effects research: Advances through meta-analysis (pp. 53-80). Mahwah, NJ, USA: Erlbaum.

Scheufele, D. A., \& Tewksbury, D. (2007). Framing, agenda setting, and priming: The evolution of three media effects models. Journal of Communication, 57(1), 9-20.

https://doi.org/10.1111/i.0021-9916.2007.00326.x

Stiff, J. B. (1986). Cognitive processing of persuasive message cues: A meta-analytic review of the effects of supporting information on attitudes. Communication Monographs, 53(1), 75-89. https://doi.org/10.1080/03637758609376128

Szabo, A. (2020). Immediate and persisting effects of controversial media information on young people's judgement of health issues. Europe's Journal of Psychology, 16(2), 249-261. https://doi.org/10.5964/ejop.v16i2.1929

Van der Weerd, W., Timmermans, D. R., Beaujean, D. J., Oudhoff, J., \& van Steenbergen, J. E. (2011). Monitoring the level of government trust, risk perception and intention of the general public to adopt protective measures during the influenza A (H1N1) pandemic in the Netherlands. BMC Public Health, 11(1). Article 575. https://doi.org/10.1186/1471-2458-11-575

World Health Organization (2020, March 11). WHO Director-General's opening remarks at the media briefing on COVID-19 - 11 March 2020. https://www.who.int/dg/speeches/detail/whodirector-general-s-opening-remarks-at-the-media-briefing-on-covid-19---11-march-2020 
Table 1

2 Frequency (and percent) of decrease, no change and increase in the ratings of four measures in two groups receiving either uncertain or certain 3 information and the statistical difference between them based on Chi-square.

\begin{tabular}{|c|c|c|c|c|c|c|c|c|}
\hline \multirow[t]{2}{*}{ Measure } & \multicolumn{3}{|c|}{ Uncertain Information Group $(n=53)$} & \multicolumn{3}{|c|}{ Certain Information Group $(n=58)$} & \multicolumn{2}{|c|}{ Chi-Square } \\
\hline & Decrease & No Change & Increase & Decrease & No Change & Increase & $\chi^{2}$ & $p$ \\
\hline Knowledge & $2(4 \%)$ & $25(47 \%)$ & $26(49 \%)$ & $2(3 \%)$ & $41(71 \%)$ & $15(26 \%)$ & 6.62 & .037 \\
\hline Concern & $14(26 \%)$ & $34(64 \%)$ & $5(9 \%)$ & $5(9 \%)$ & $51(88 \%)$ & $2(3 \%)$ & 8.74 & .013 \\
\hline Control & $5(9 \%)$ & $36(68 \%)$ & $12(23 \%)$ & $1(2 \%)$ & $31(53 \%)$ & $26(45 \%)$ & 7.99 & .018 \\
\hline Care & $2(4 \%)$ & $45(85 \%)$ & $6(11 \%)$ & $1(2 \%)$ & $16(28 \%)$ & $41(71 \%)$ & 40.04 & $<.001$ \\
\hline
\end{tabular}

4 Note: Percentages are rounded to integers and, therefore, they may not add up to exactly $100 \%$ in all instances (i.e., $\pm 1 \%$ calculation error). 


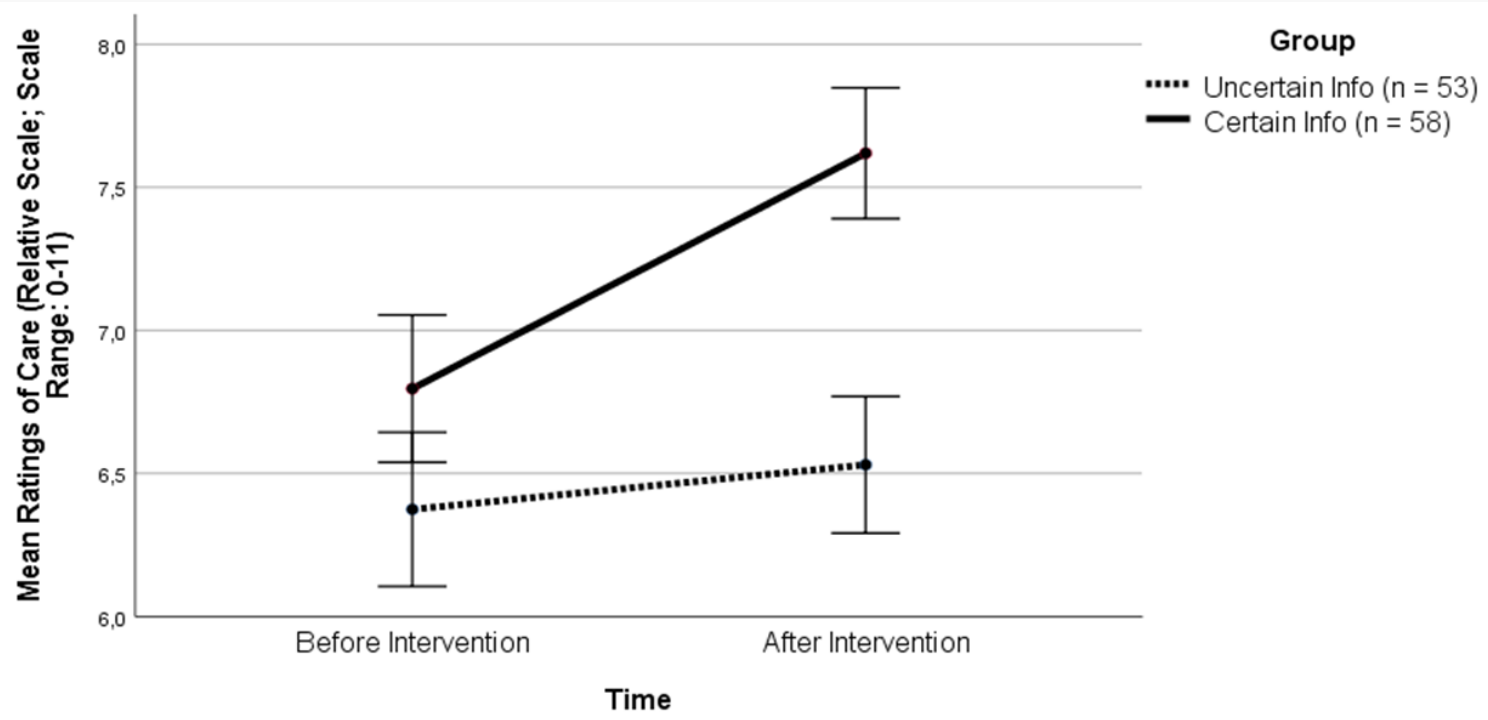

Covariates appearing in the model are evaluated at the following values: Age $=25,04$, Teacher $/$ University Student $=1,84$

Error bars: $95 \% \mathrm{Cl}$

Figure 1

7 Group by time interaction in perceived personal care. The groups differ after the intervention,

8 but not at the baseline (before the intervention). 